\title{
RESENHAS
}

LÓPEZ-RUIZ, Osvaldo. 2007. Os executivos das transnacionais e o espírito do capitalismo : capital humano e empreendedorismo como valores sociais. Rio de Janeiro : Azougue.

\section{A VIDA COMO CARREIRA}

\author{
Rafael Alves da Silva
}

A preocupação com o universo empresarial nunca esteve tão presente. Faz algum tempo, multiplicaram-se as publicações destinadas a auxiliar os profissionais a desenvolverem habilidades além das técnicas, como relacionamento, liderança, criatividade, controle emocional etc. Manifestações no campo artístico refletem esse interesse e apontam para transformações que ocorreram e ainda estão em curso em nossa sociedade. Como exemplo, podemos lembrar a peça teatral $O$ método Grönholm, de Jordi Galcerán; o filme de Marcelo Piñeyro, El Método (no Brasil O que você faria?), baseado na peça; Direktøren for det hele (O grande chefe), do cineasta Lars Von Trier; o romance La question humaine, de Emmanuel François; entre outros. Mesmo a televisão procura recriar tal universo em seus programas, com reality shows baseados na estratégia e competição entre os participantes ou reproduzindo diretamente o meio empresarial como em $O$ aprendiz, da People and Arts e Record. Convém lembrar o comentário do filósofo francês Gilles Deleuze, que diz: "Se os jogos de televisão mais idiotas têm tanto sucesso é porque exprimem adequadamente a situação de empresa".

Esses poucos exemplos têm apenas a intenção de apontar como a temática empresarial está presente atualmente. Porém, talvez não devamos pensar apenas em como tem crescido o interesse por assuntos reconhecidos como sendo do meio empresarial, mas também como a lógica presente no ambiente corporativo vem se inscrevendo na sociedade. Até que ponto a forma-empresa tem adentrado no cotidiano? Seja na escola, na família, enfim, até que ponto e como está sendo utilizada pelas pessoas uma racionalidade de tipo empresarial para a condução de suas vidas?

O livro Os executivos das transnacionais e o espírito do capitalismo: capital humano e empreendedorismo como valores sociais, de Osvaldo López-Ruiz, vem explicitar características da sociedade contemporânea e, na medida em que refaz o percurso de diversas transformações no modo de pensar a economia e a sociedade, apresenta o momento de "invenção" de certos conceitos e teorias que embasam valores e crenças tidos hoje, muitas vezes, como naturais.

Atualizando algumas das questões colocadas por Max Weber há mais de cem anos em A ética protestante e o espírito do capitalismo, López-Ruiz busca identificar alguns dos valores que orientam a conduta das pessoas e que possibilitam o funcionamento do sistema capitalista agora, no início do século XXI. Por entender que as corporações transnacionais representam instituições paradigmáticas do mundo social na atualidade, escolhe os executivos dessas empresas como objeto de estudo para, por meio da análise da conduta e do discurso destes, entender transformações socioculturais que vêm ocorrendo de forma global.

A partir daí, realiza uma abrangente pesquisa de campo, entrevista diversos executivos e consultores de várias corporações, participa de cursos, recruitments (palestras de recrutamento), feiras e outros eventos voltados para tal público, além de acompanhar sistematicamente jornais de negócios e revistas voltadas para esse segmento. Esse contato lhe permite identificar um conjunto de conceitos, tais como "inovação", "criatividade", "flexibilidade", "empreendedorismo" e "capital humano", e observar que possuem uma conotação e uma valoração social que pautam a conduta das pessoas, ultrapassando o meio corporativo.

Associado a tal pesquisa empírica, desenvolve um forte trabalho teórico apresentando a "genealogia" do executivo. Valendo-se das análises de Sombart, Weber e Schumpeter, recupera a figura do "empreendedor" do início do século XX e a discussão daquele momento a respeito do "espírito do capitalismo".

Noutro momento, após a Segunda Guerra Mundial, surge a figura do "empregado dependente", indivíduo que López-Ruiz associa à "conformidade", longe da "vontade de inovar" ou da "iniciativa individual", traços dos homens de empresa descritos cerca de 50 anos antes. Analisa o trabalho de William H. Whyte Jr., que publica The Organization Man na década de 1950, em que aponta que o jovem norte-americano da época tinha como único objetivo trabalhar em uma grande companhia. Pela forma de vida assumida, estavam mais ligados à grande corporação do que haviam estado as gerações precedentes e já não se interessavam pelas finanças 
como ocorrera com os estudantes da década de 1920.

Na mesma linha, recupera o trabalho de C. Wright Mills, notadamente White Collar: the American Middle Classes, do início da década de 1950, em que o sociólogo norte-americano enxergava o declínio do empresário livre e a ascensão do empregado dependente na sociedade americana. Segundo este, de forma diferente da Europa, nos Estados Unidos, as classes médias haviam surgido como pequenos empresários, e, no século XIX, o agricultor independente e o pequeno homem de negócios, de forma que uma porção significativa da população era possuidora dos meios de produção. Em meados do século XX, com a industrialização acelerada e a expansão das grandes corporações, ocorria um processo de concentração da propriedade, representando o fim da possibilidade de o indivíduo ter um meio de vida independente, levando Mills a concluir que os Estados Unidos deixavam de ser uma nação de pequenos capitalistas, passando a ser um país de empregados, mas a ideologia adequada ao primeiro tipo subsistia.

López-Ruiz está preocupado com o ethos que motiva e impulsiona o capitalismo na fase contemporânea. Dessa forma, ao analisar o quadro descrito, o "homem organização" de Whyte e os "colarinhos brancos" de Mills, pergunta: "Como seria possível manter e incrementar a prosperidade econômica da sociedade afluente se os atuais responsáveis por seu funcionamento se mostravam pouco estimulados à criatividade, à inovação, a correr riscos e a assumir a aventura de novos desafios?" O autor propõe que "a Escola de Chicago, com a teoria do capital humano, ofereceu uma das mais sofisticadas formulações para sair desse impasse" (LÓPEZRUIZ, 2007b, p. 67).

O período de opulência do desenvolvimento econômico posterior à Segunda Guerra trazia outro problema além da aparente apatia da classe média. "Os fatores originários da produção, terra, capital e trabalho mostravam um crescimento individual que, somado, era significativamente inferior ao crescimento total da economia" (idem, p. 55). O economista Theodore W. Schultz formula sua hipótese de que a explicação deveria ser buscada na acumulação de riqueza humana que era excluída das medidas convencionais de "horas-homem trabalhadas" e capital tangível. Contudo, López-Ruiz se encarrega de mostrar que a originalidade da proposta desse economista não estava em introduzir o capital humano no cálculo econômico. Aponta que tal tema foi "descoberto" diversas vezes e outros autores preocuparam-se com a riqueza do "capital vivo" (que Schultz chamará de capital humano). Por exemplo, num artigo de Nicholson, de 1891, intitulado O capital vivo do Reino Unido, aparecem os principais elementos da argumentação de Schultz.

Entretanto, López-Ruiz explicita as diferenças entre as concepções desses dois autores: "Para Schultz, o valor do stock 'capital humano' não é inferido de uma analogia com o 'não humano' - ou 'morto' -, como em Nicholson. 'Capital humano' para ele são as próprias 'destrezas e habilidades' - concretas - 'adquiridas por engenheiros, químicos e outros trabalhadores'. Aqui se enraíza a diferença fundamental entre os enfoques dos dois autores. O que para um é uma estimativa da riqueza que representam os seres humanos em si mesmos em comparação com o "capital morto" que contabiliza a economia e que é externo a eles, para o outro trata-se de estabelecer quanto valem para o mercado certas particularidades, certas condições humanas que o homem pode desenvolver e que valor econômico elas podem produzir" (idem, p. 57).

Além disso, aponta que, onde Nicholson fala de "custos", um gasto derivado da utilização de mercadorias e serviços para a satisfação de necessidades humanas, Schultz falará de "investimento". "Dessa forma curiosa reaparece em Schultz o ethos protestante descrito por Weber, contudo, dessa vez, não mais pregando deixar o consumo em favor da poupança, mas em substituir o que era entendido como consumo por investimento" (ibidem).

As idéias relativas ao capital humano sofreram resistências no início, tanto de cunho ético como críticas relacionadas ao sentido de custo-benefício dado à educação e na definição de suas políticas, ou em justificar os investimentos no homem exclusivamente pelo retorno. Gary S. Becker, por exemplo, foi vaiado pelo auditório ao propor, em 1960, considerar as crianças como "bens de consumo duráveis". No entanto, tais entraves foram gradativamente superados na segunda metade do século XX e autores como Becker e Schultz, criticados por seus colegas, anos depois, foram reconhecidos e viram suas idéias difundidas e tornadas incontestáveis, em outras palavras, passaram a ser parte do mainstream da economia. Schultz recebeu o Prêmio de Ciências Econômicas em Memória de Alfred Nobel em 1979 e Becker foi galardoado com o mesmo em $1992^{1}$.

\footnotetext{
1 Esses prêmios são, normalmente, referidos como prêmios Nobel. Mas a fundação Nobel concede, desde 1901, prêmios para realizações nas áreas de Física, Química, Medicina, Literatura e para a Paz. Em 1968, o Sveriges Riksbank, o banco
} 
López-Ruiz faz uma reconstituição bastante rica, que não podemos reproduzir aqui, do percurso de tais idéias, os vários autores, as resistências e como tais teorias contribuíram para a transformação do empregado dependente no executivo atual, que é o objeto de sua análise. Assim, o capital humano foi "definitivamente inventado" no início da década de 1960, na Universidade de Chicago, após ter sido "descoberto" diversas vezes, afirma o autor. Tal teoria amplia o conceito de capital incorporando condições e habilidades humanas que podem e devem ser desenvolvidas e transforma "consumo" em "investimento". Afasta-se da teoria econômica clássica, na qual o trabalho é pensado como um fator originário da produção, e passa a pensá-lo, assim como ao próprio trabalhador, como um meio de produção produzido. “A ciência econômica, nesse caso, não cria só uma teoria sobre a economia; cria um repertório de interpretação que nos permite pensar e pensar-nos de maneira tal que não nos resulte repulsiva a imagem do humano como riqueza - como o havia sido em tempos de J. S. Mill. A partir de seus postulados 'cientificamente verificáveis', o humano passa a ser entendido como uma forma de capital e, portanto, o "capital humano" e tudo o que se faça para incrementá-lo é investido de um valor positivo: cada pessoa deve - porque é economicamente conveniente, mas também porque é "moralmente bom' - aumentar suas habilidades, competências e destrezas a partir de 'investimentos' constantes” (idem, p. 62).

Assim, na análise de López-Ruiz, com a sua proposta de um deslocamento conceitual-valorativo do consumo para o investimento, estamos diante da emergência de uma sociedade organizada a partir do modelo de empresa. Ou, em outras palavras, uma sociedade na qual cada indivíduo é levado a incorporar a forma-empresa como meio de organizar, não apenas a sua atividade profissional, a sua carreira, mas a sua própria vida.

E, voltando aos problemas de Whyte e Mills, em que os responsáveis em manter a prosperidade da "sociedade afluente" estavam pouco motivados, lembrando o problema da classe média que não era mais proprietária dos meios de produção como havia sido no passado, vemos com López-Ruiz que, curiosamente, será a teoria econômica a encarregada de converter as classes médias não proprietárias, os empregados dependentes das grandes corporações, novamente em proprietários: “A partir de então, os não-proprietários de bens tangíveis seriam proprietários de suas próprias habilidades, competências e destrezas. Mas, como tais, seriam também responsáveis por sua manutenção e incremento. A propriedade desse capital intangível lhes garantiria sua independência individual e abriria as portas à sua participação nas demais esferas do social. $\mathrm{O}$ indivíduo podia agora reivindicar seus direitos e sua individualidade, e o consumo-investimento seria a forma para fazê-lo porque, através disso, ele afiançaria sua propriedade sobre si mesmo" (idem, p. 68).

Dessa forma, partindo dos executivos, de seus hábitos e discursos com relação ao próprio trabalho, LópezRuiz investiga a formação de um conjunto de valores cada vez mais presentes na sociedade, uma lógica e uma racionalidade que não são exclusivas das grandes corporações e dos postos mais altos da hierarquia empresarial.

As publicações do segmento de "gestão da carreira" são consumidas avidamente por um público muito maior do que os que poderiam ser chamados de executivos. Citando apenas um exemplo, Quem mexeu no meu queijo?, de Spencer Johnson, que trata da capacidade de se adaptar e se antecipar a mudanças, vendeu mais de 11 milhões de livros em todo o mundo, em 26 línguas. A lógica descrita por López-Ruizé a que permite a um periódico trazer na capa: "O salário vai acabar (e esta é uma boa notícia)" (Exame, 2006) - a matéria aponta as possibilidades do trabalhador livre para empreender e as vantagens em receber pelo cumprimento de metas. Tal descrição possibilita também uma maior compreensão da frase de Sérgio Moreira, em 2002 presidente do Sebrae, de que "o empreendedorismo não é o privilégio da iniciativa privada, o empreendedorismo é a atitude de um povo" (LÓPEZ-RUIZ, 2007b, p. 79).

Como comentamos em outra oportunidade, "não se têm mais amigos, mas network, não se gozam férias, mas investe-se em qualidade de vida. Tudo é movido pelo cálculo e interesse. Não pode ser apenas força de expressão [...] escolas fazerem sua propaganda aconselhando os pais a investirem na educação dos filhos, pois eles são a melhor aposentadoria" (SILVA, 2006, p. 159-160).

O filósofo André Gorz, tratando de mudanças recentes no capitalismo, analisa que "desfeitas as relações salariais convencionais, resolveu-se a questão a respeito do modo como o capital consegue exercer poder sobre os homens e é capaz de mobilizar a todos: os empregados têm de se tornar empresas [...] Na briga com a

central da Suécia, instituiu o "Prêmio de Ciências Econômicas em memória de Alfred Nobel", que é incorretamente referido pelos economistas como um "Prêmio Nobel da Economia". Esse prêmio não tem nenhuma ligação com Alfred Nobel, não sendo pago com o dinheiro privado da Fundação Nobel, mas com dinheiro público do banco central sueco. 
concorrência, eles serão forçados a internalizar a pressão trazida pela lógica de obtenção do máximo de proveito possível. No lugar daquele que depende do salário, deve estar o empresário da força de trabalho, que providencia sua própria formação, aperfeiçoamento, plano de saúde etc. 'A pessoa é uma empresa'. No lugar da exploração entram a auto-exploração e a autocomercialização do 'Eu S/A', que rendem lucros às grandes empresas, que são clientes do auto-empresário" (GORZ, 2005, p. 10).

E, na tentativa de valorizar o próprio capital, como empresário de si mesmo, as mais diferentes atividades serão encaradas como passíveis de algum retorno econômico. Dessa forma, interessam, por exemplo, conhecer vinhos, pois pode ser um investimento útil no trato com as pessoas e na conquista de clientes. Qualquer aprendizado poderá ser encarado dentro dessa lógica. Em outro exemplo, uma das capas da revista Você $S / A$ traz: “'Eu negociei a vida do meu filho' - o empresário Alexander Lucinski passou 15 dias negociando com seqüestradores. Dessa experiência, tirou lições para a vida e para o trabalho" (Você S/A, 2005b).

Tais observações da cena contemporânea tornam-se mais inteligíveis com o trabalho de López-Ruiz, pois este permite compreender algumas das transformações ocorridas na sociedade que tornaram possível tal situação.

Em resumo, Os executivos das transnacionais e o espirito do capitalismo gira em torno de cinco teses. A primeira sustenta que um ethos vem se formando, o qual possibilita pensar o humano como uma forma de capital. Não significa apenas uma ampliação do conceito de capital para habilidades humanas, mas também o surgimento de uma ética social que permite às pessoas orientarem suas ações por meio de uma lógica semelhante à aplicada a outras formas de capital, realizando investimentos em suas capacidades a fim de obter benefícios futuros. Na segunda tese, vemos que vem se realizando uma transformação no conceito de consumo, que passa a ser encarado como investimento, seja "investimento em educação" para aumentar seu próprio capital humano, seja em um celular que cause melhor impressão ou em uma viagem, já que também é necessário "investir em qualidade de vida". A terceira discute o empreendedorismo como fenômeno de massas, e é um dos pontos fortes em que se verifica a abrangência da discussão, não se limitando somente ao objeto da pesquisa, os executivos, mas realmente apontando para ressonâncias na sociedade como um todo, visto que esses valores são agora atributos que todos devem manifestar e que podem ser aprendidos, não sendo mais características exclusivas de determinados indivíduos como outrora observou Schumpeter. Temos, na quarta tese, a internalização do afã de lucro, cada pessoa como empresário de si próprio, devendo cuidar de si como uma empresa e tendo tal afã de lucro como praticamente seu único motivo na vida. E vemos, na quinta tese, a ciência como fundamento do ethos, a ciência ocupando o lugar que antes fora da religião na definição do que é "verdadeiro".

Em sua conclusão, juntamente com as considerações finais que reorganizam as teses que foram desenvolvidas no livro, López-Ruiz apresenta um pequeno histórico das doutrinas da administração e suas diversas correntes, comentando os diferentes conjuntos de valores que cada uma trouxe consigo e como eles permanecem por mais tempo que as próprias correntes da administração, efêmeras por natureza. Da administração científica ao que ele propõe chamar de capitalismo humano e empreendedorismo, passando por diversas outras em diferentes períodos do século XX.

Nesse momento, analisa como os valores sociais comentados, o ethos dos executivos que argumenta se estender para a sociedade como um todo, contribuem para a manutenção do sistema capitalista na fase contemporânea. Em suas palavras: "Se os sujeitos econômicos capitalistas, se os empreendedores não são apenas alguns poucos - se ser empreendedor passa a ser o atributo de um povo - cada indivíduo deverá (quererá!) aumentar o valor da sua empresa e entregará todo o seu amor e dedicação a seu negócio. Quem pode duvidar da importância dessa fonte de energia, como diria Sombart, para o sistema econômico no século que se inicia? Quem pode duvidar da saúde do capitalismo com tantas almas entregando-se a seus negócios como o único interesse da vida? Quem pode duvidar do entusiasmo de tantos entrepreneurs?" (LÓPEZ-RUIZ, 2007b, p. 303).

Um problema que pode ser levantado aqui é como ficaria essa "saúde do capitalismo" na conjuntura atual de desemprego, num momento em que a produtividade aumenta reduzindo postos de trabalho ${ }^{2}$. Ou seja, se a

2 Como exemplo, em uma entrevista ao jornal Folha de S.Paulo, de 22 de outubro de 2006, o sociólogo Ricardo Antunes comenta: "[O economista norte-americano] Jeremy Rifkin publicou um artigo no [The] Guardian em 2004 dizendo que, entre 1995 e 2002, a China perdeu 15 milhões de trabalhadores industriais crescendo $10 \%, 12 \%$ ao ano. O crescimento não é sinônimo de inclusão no trabalho". 
fonte de energia do sistema estaria no fato de os empreendedores não serem "apenas alguns poucos", como esse quadro seria possível com tantos indivíduos aparentemente impossibilitados de buscar qualquer valorização de seu capital humano, tão distantes de parecerem uma empresa?

López-Ruiz não se detém nesse ponto, mas, pela lógica que descreveu, pela responsabilidade de cada um por sua própria empregabilidade, podemos inferir que as concepções do capital humano e empreendedorismo seriam responsáveis por justificar, para os próprios desempregados, a sua condição. Dito de outro modo, se o ethos descrito pelo autor avança pela sociedade e passa a embasar a conduta dos indivíduos, temos um cenário em que a corrida pela valorização do próprio capital confere energia ao sistema, também legitimando a situação daqueles que estiverem à margem da disputa. E isso se manifesta quando um consultor econômico, ou de gestão de carreiras, vai à televisão defendendo que mesmo os trabalhadores que recebem um salário mínimo precisam se preocupar em investir na própria formação.

Susan George simulou a elaboração de um relatório sobre os problemas para a manutenção do capitalismo e suas possíveis soluções, de forma a traçar os desdobramentos do pensamento neoliberal e da sociedade contemporânea. Segundo os especialistas "fictícios", o mercado aceita os melhores e rejeita os demais, conforme o princípio da concorrência. Porém, os "demais" estão em número muito maior, ameaçando o sistema. Por diversos motivos, não "compensaria" a aplicação de modelos como os de Auschiwitz. Dessa forma, "a seleção das 'vítimas' não deverá ser preocupação de ninguém a não ser das próprias 'vítimas'. Elas mesmas se escolherão pelos critérios de incompetência, incapacidade, pobreza, ignorância, preguiça, criminalidade e assim por diante" (GEORGE, 2002, p. 89); em suma, farão parte do grupo dos perdedores.

Outra perspectiva que poderia polemizar com posições de López-Ruiz seria a do próprio homem de empresa, o executivo, o consultor, o gestor de recursos humanos que por ventura lesse o livro - mesmo algum entrevistado. Provavelmente o executivo que o autor ouviu dizer "eu gosto, eu gosto, eu gosto" (LÓPEZRUIZ, 2007b, p. 303), sentir-se-ia incomodado com o comentário do sociólogo - recuperando a tese de Sombart sobre o amor ao negócio manifestado nos empresários - a respeito do "empobrecimento humano" (ibidem). Tal crítico, provavelmente, faria objeções quanto a considerar o capital humano como "inventado" em determinado momento, argumentaria que, tendo embasamento científico, respaldado pelas análises econômicas, haveria ocorrido na década de 1960, após as diversas "descobertas", a formulação correta desse conceito e não uma simples construção. Ou seja, a importância em se valorizar o capital humano, a necessidade do empreendedorismo para responder a um mercado que só tem lugar para os melhores, não seria uma "invenção", mas uma constatação de algo que é real e inevitável.

Se assim for, temos uma situação interessante em que o leitor neoliberal, empenhado em criticar os argumentos desse livro, não teria óbices a colocar em relação ao histórico das idéias apresentadas pelo autor, ficaria inclusive satisfeito com a constatação de certos conceitos terem surgido em resposta a problemas da economia como ciência, opondo-se apenas ao caráter crítico que o trabalho de López-Ruiz assume, simplesmente ao refazer o percurso de formação de tais idéias. E aqui faz todo o sentido a frase do filósofo Michel Foucault de que "é exatamente contra os efeitos de poder próprios de um discurso científico que a genealogia deve travar combate".

Por outro lado, talvez mesmo esse aspecto crítico do texto de López-Ruiz consiga ser ironicamente aproveitado pelos discursos do capital humano. Vale lembrar que os diversos alertas de Richard Sennett em A corrosão do caráter, sobre as conseqüências pessoais das mudanças recentes no capitalismo, colocaram o sociólogo como um dos sete principais entrevistados durante os sete anos da revista Você $S / A$ (2005a, p. 46-47). Seus comentários sobre a reestruturação produtiva e seu impacto na vida das pessoas foram recebidos como necessidade de se desenvolver mais, seja nos conhecimentos técnicos para tentar garantir o emprego, seja no aprendizado emocional para resistir ao aumento da pressão e do estresse. Mas essas são somente divagações que nos permitimos para sugerir possíveis problematizações com o texto e, ao mesmo tempo, destacar sua consistência teórica.

Por último, vale comentar que, assim como o leitor simpático às idéias relacionadas ao capital humano pode passar por todo o livro e se incomodar ao final, pode apreciar o desenho do quadro, mas não gostar de seu resultado, num outro sentido, o leitor crítico às idéias neoliberais pode sofrer de certa ansiedade por uma tomada de posição explícita do autor. Mas aí está um ponto forte de sua crítica, pois ela surge no movimento do próprio livro, assumindo maior consistência do que se fosse simplesmente formulada já na introdução. Por tudo isso, esse livro traz discussões cada vez mais presentes na contemporaneidade, porém aqui de uma forma 
crítica, com uma argumentação muito bem embasada nas pesquisas empírica e teórica desenvolvidas pelo autor, possibilitando ao leitor aguçar sua percepção e compreender melhor transformações em curso na sociedade e em sua "empresa".

Rafael Alves da Silva (rafaelcotuca@yahoo.com.br) é Graduado em Sociologia e Ciência Política pela Universidade Estadual de Campinas (Unicamp), mestrando em Sociologia dessa mesma instituição e membro do grupo Conhecimento, Tecnologia e Mercado (CTeMe).

\section{REFERÊNCIAS BIBLIOGRÁFICAS}

GEORGE, S. 2002. O relatório Lugano. São Paulo : Boitempo.

GORZ, A. 2005. O imaterial : conhecimento, valor e capital. São Paulo : Anablume.

LÓPEZ-RUIZ, O. 2007a. Ethos empresarial : el “capital humano” como valor social. Estudios Sociológicos, v. 25, n. 74, p. 399-425, maio-ago.

.2007b. Os executivos das transnacionais e o espirito do capitalismo : capital humano e empreendedorismo como valores sociais. Rio de Janeiro : Azougue.

MILLS, C. W. 1969. A nova classe média [White Collar]. Rio de Janeiro : Zahar.

NICHOLSON, J. S. 1891. The Living Capital of the United Kingdom. The Economic Journal, v. 1, p. 95-107, Mar.

SANTOS, L. G. 2007. Apresentação. In : LÓPEZ-RUIZ, O. Os executivos das transnacionais e o espírito do capitalismo : capital humano e empreendedorismo como valores sociais. Rio de Janeiro : Azougue.

SCHULTZ, T. W. 1973. O capital humano : investimento em educação e pesquisa. Rio de Janeiro : Zahar.

SILVA, R. A. 2006. A exaustão de Sísifo : articulação entre toyotismo, neoliberalismo e teoria do capital humano. Mediações, Londrina, v. 11, n. 1, p. 147-162.

WHYTE JUNIOR, W. H. 1956. The Organization Man. New York : Simon \& Schuster.

\section{OUTRASFONTES}

EXAME. 2006. São Paulo, n. 868, 18.maio.

VOCÊ S/A. 2005a. São Paulo, n. 86, ago. .2005b. São Paulo, n. 88, out. 